\title{
New Assessment of Gleason Grading System in Prostatic Adenocarcinoma
}

\author{
Prostat Karsinomunda Gleason Dereceleme Sisteminin Yeni Değerlemesi
}

\section{Şükran Sarıkaya Kayıpmaz}

Dr. Lütfi Kırdar Kartal Training and Research Hospital, Clinic of Pathology, Istanbul, Turkey

\section{Introduction}

Gleason gradinge system remains the most widely used system and one of the most useful predictors of prognosis of prostate cancer. Donald F. Gleason in 1966 created a unique grading system for prostatic carcinoma based solely on the architectural pattern. Five distinct architectural patterns are identified, being 1 most differentiated and 5 least differentiated. first after the declaration, the serum prostate specific antigen (PSA) began to be widely used, with numerous examples $18 \mathrm{~g}$ needle in needle biopsies made, it is noted in radical prostatectomy (RP) multiple tumor nodules, and basal cells shown immunohistochemically, adenocarcinoma of the prostate to treatment, such as radiotherapy and chemotherapy was added and new variants were defined. After all these developments the International Society of Urological Pathology (ISUP) introduced major modifications to the Gleason system in 2005. Subsequent proposals for slight modifications of the ISUP grading system are were declared by the ISUP in 2010.

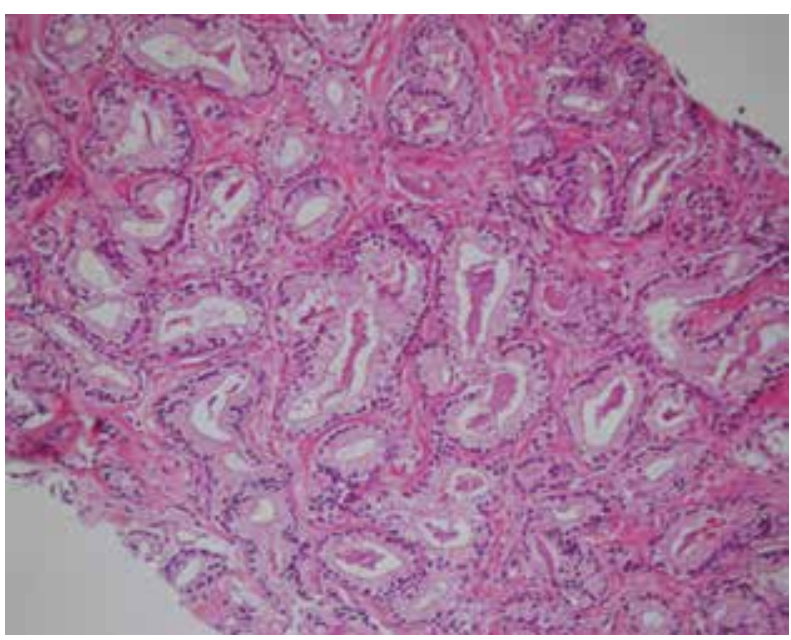

Figure 1. Gleason grade 3; closely packed uniform sized and shaped large glands; large variably sized and shaped glands, some with infolding; uniform medium sized glands; variably sized glands (HE x20)
Gleason score 2-4 is markedly reduced over the years. Helpap and Egevad (1) demonstrated Gleason score 5 on biopsy, which would encompass $2+3=5$ or $3+2=5$, also decreased from $12.2 \%$

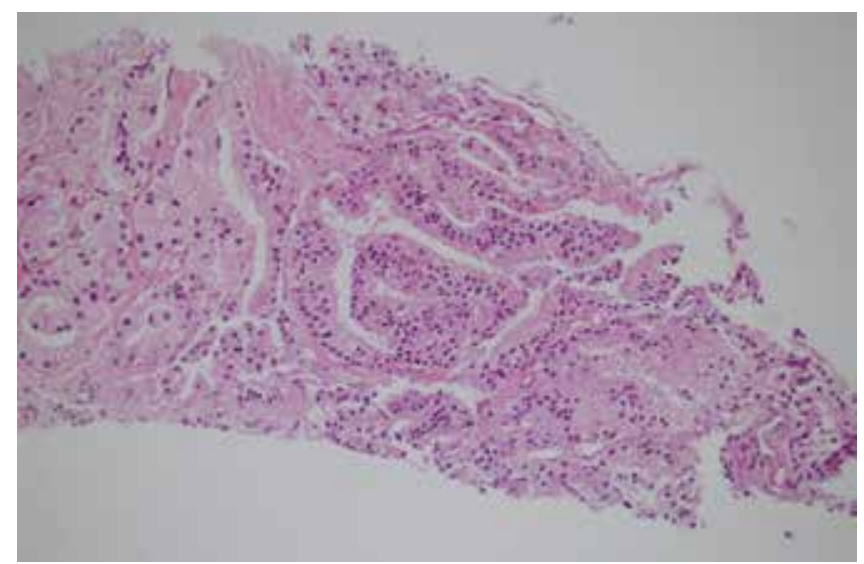

Figure 2. Gleason grade 4; large irregular cribriform glands, poorly-formed glands, fused poorly-formed glands (HE x200)

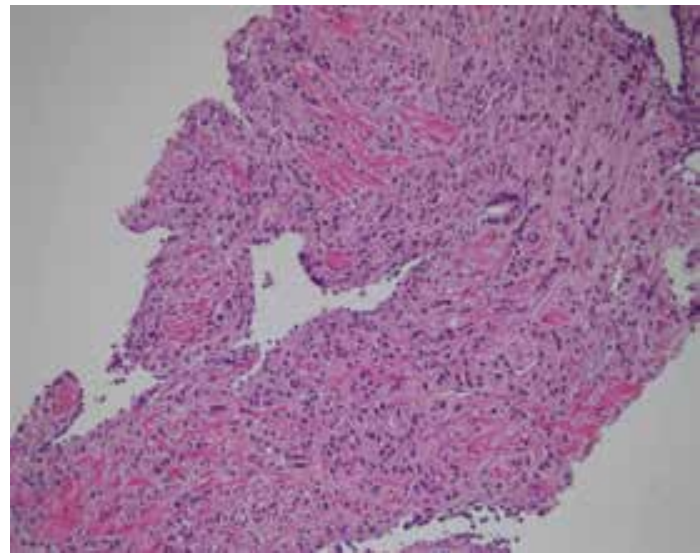

Figure 3. Gleason grade 5; small nests and cords of tumor with scattered clear vacuoles; individual cells, nests and cords of cells with only vague attempt at lumina formation (HE x200) 
to $0.3 \%$. Hernandez et al. (2) stated in 2008 biochemical recurrence and local recurrence of Gleason score 6 or less prostate cancer case was reported that the rare. Ross et al. (3) mentioned in 2012 that, patients with Gleason score $\leq 6$ in the post-ISUP have an excellent prognosis with a 5 -year biochemical cure rate of $94.6 \%$ following RP. The Gleason score ranges from 2 to 10. in this range, but in fact it might seem to have gleason 6 intermediear prognosis the prognosis is good.

Today's cases of Gleason score 6 are a homogenous group of tumors lacking cribriform and poorly formed glands with a better prognosis (Figure 1, 2, 3) (4). Esserman (5), propose the term indolent lesion of epithelial origin, or indolent lesion of epithelial origin, for indolent to fast-growing lesions those lesions (currently labelled as cancers).

Until today combining of Gleason scores into a three-tiered grouping $(6,7,8,9,10)$ is used most frequently for prognostic and therapeutic purposes. these groups contains some problems and deficiencies. A Gleason score 7 may represent contain a Gleason score of $3+4$ and Gleason score of $4+3$ but their prognosis is different. Similarly, the prognosis is different in the range of 8-10. the same score shouldnt be a different prognosis. There are 2 large studies that will bring clarity to the issues in the prognostic groups. These studies have a different prognostic group was studied. Prognostic grade group into a five -tiered grouping Gleason score $\leq 6 ; 3+4 ; 4+3 ; 8 ; 9-10$.

The first study Pierorazio et al. (6) analyzed 7869 men from the John Hopkins Radical Prostatectomy Database (1982-2011) for men undergoing RP without a tertiary pattern from 2004 to 2013 and identified 7869 men. Significant differences were noted among the Gleason grade groups at biopsy; differences were noted in the race, PSA level, clinical stage, number of positive cores at biopsy and the maximum percentage of positive cores among the Gleason grade groups at RP. With a median (range) follow-up of 2 (1-7) years, 5 -year biochemical recurrence free rates for men with Gleason grade $\leq 6,3+4,4+3,8$ and 9-10 tumours at biopsy were 94.6, 82.7, 65.1, 63.1 and $34.5 \%$, respectively and 96.6, 88.1, 69.7, 63.7 and $34.5 \%$, respectively, based on RP pathology.

Second study Epstein et al. (7), analyzed records of 20.845 consecutive men were treated by RP and 5501 men treated with radiotherapy between 2005 and 2014 using multi-institutional and multimodal therapy data. Large differences in recurrence rates between both Gleason $3+4$ versus $4+3$ and Gleason 8 versus 9. The hazard ratios relative to Gleason score 6 were 1.9, 5.1, 8.0 and 11.7 for Gleason scores $3+4,4+3,8$ and 9-10, respectively.

New prognostic grade group consists of 5 sub-groups. The lowest grade group having the best prognosis gleason score 6 . located $3+4$ and $4+3$ old classification in the same group has taken place in different groups that have a different prognosis. Eight-10 with different prognosis is that a large group was divided into 2 subgroups. This is as a result of the groups were homogeneous and have the same outcome in itself.

1. Grade group 1 (Gleason score $\leq 6)$; only individual discrete well formed glands,

2. Grade group 2 (Gleason score $3+4=7$ ); predominantly wellformed glands with lesser component of poorly- formed/fused/ cribriformglands

3. Grade group 3 (Gleason score $4+3=7$ ); predominantly poorlyformed/ fused/cribriform

glands with lesser component of well-formed glands,

4. Grade group 4 (Gleason score 8); only poorly-formed/fused/ cribriform glands or predominantly well-formed glands and lesser component lacking glands or predominantly lacking glands and lesser component of well-formed glands

5. Grade group 5 (Gleason scores 9-10); lacks gland formation (or with necrosis) with or poorly formed/fused/cribriform glands.

\section{Ethics}

Peer-review: Internal peer-reviewed.

\section{References}

1. Helpap B, Egevad L. The significance of modified Gleason grading of prostatic carcinoma in biopsy and radical prostatectomy specimens. Virchows Arch 2006;449:622-627.

2. Hernandez DJ, Nielsen ME, Han M, Trock BJ, Partin AW, Walsh PC, Epstein JI. Natural history of pathologically organ-confined (pT2), Gleason score 6 or less, prostate cancer after radicalprostatectomy. Urology 2008;72:172176.

3. Ross HM, Kryvenko ON, Cowan JE, Simko JP, Wheeler TM, Epstein JI. Do adenocarcinomas of the prostate with Gleason score (gs) $\leq 6$ have the potential to metastasize to lymph nodes? Am J Surg Pathol 2012;36:13461352.

4. Lotan TL, Epstein Jl. Gleason grading of prostatic adenocarcinoma with glomeruloid features on needle biopsy. Hum Pathol 2009;40:471-477.

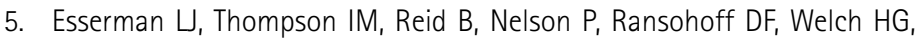
Hwang S, Berry DA, Kinzler KW, Black WC, Bissell M, Parnes H, Srivastava S. Addressing overdiagnosis and overtreatment in cancer: a prescription for change. Lancet Oncol 2014;15:234-242.

6. Pierorazio PM, Walsh PC, Partin AW, Epstein Jl. Prognostic Gleason grade grouping: data based on the modified Gleason scoring system. BJU Int 2013;111:753-760.

7. Epstein JI, Zelefsky MJ, Sjoberg DD, Nelson JB, Egevad L, Magi-Galluzzi C, Vickers AJ, Parwani AV, Reuter VE, Fine SW, Eastham JA, Wiklund P, Han M, Reddy CA, Ciezki JP, Nyberg T, Klein EA. A contemporary prostate cancer grading system: a validated alternative to Gleason score. Eur Urol 2016;69:428-435. 